\title{
Building Leadership Capacity and Enacting School Improvement Policy: Voices from the Field
}

\author{
Lindy-Anne Abawi ${ }^{1,}$, Tania Leach $^{2} \&$ Julie Raitelli $^{2}$ \\ ${ }^{1}$ University of Southern Queensland, Australia \\ ${ }^{2}$ Queensland Department of Education and Training, Australia \\ *Correspondence: University of Southern Queensland, Australia. E-mail: \\ Lindy-Anne.Abawi@usq.edu.au
}

Received: March 9, 2018 Accepted: March 24, 2018 Published: March 31, 2018

doi:10.5296/ije.v10i1.12930ＵRL: https://doi.org/10.5296/ije.v10i1.12930

\begin{abstract}
Education contexts engaging in reform, operate in complex environments that require the coherent implementation of education policies. Research highlights that systems that support shared leadership, strong communication practices and a sharp focus on the articulation of shared beliefs, are positioned to support strong policy interpretation though the enactment of school improvement strategies. This paper explores the inter-connected roles of a system middle leader (regional Project Officer) and a school leader (Principal) in interpreting and enacting systemic policy and direction in a state primary school within a regional context in Queensland, Australia. The case study utilised the regional Project Officer and Principal participants as co-researchers and captured their experiences through recorded narratives and narrative inquiry conversations. The thematic data analysis provides useful information about how school leaders can work with system middle leaders and their own school's teaching teams to proactively grow the capacity, credibility and strength of teachers to translate policy into enacted school improvement strategies.
\end{abstract}

Keywords: policy translation, policy enactment; shared leadership; teacher leadership; system/school leadership; narrative, case study 


\section{Introduction}

Research in the area of school improvement policy implementation highlights the need to utilise connecting strategies across systems to directly impact on daily teaching practice (Hooge, 2016). The effectiveness of these implementation processes was found to be directly influenced by a system's ability to utilise shared leadership (Levin \& Fullan, 2009; Lewis \& Andrews, 2004; Michel, 2016) to communicate transparent expectations and provide relevant professional learning (Michel, 2016; Scott, 2013). Leadership research often focuses on the work of Principals in creating and maintaining cultures that foster distributed leadership practices (Bolden, 2011; Crowther \& associates, 2011; Gronn, 2002; Leithwood, Jantzi, \& Steinbach, 2012; Lewis \& Andrews, 2009; Spillane, Halverson, \& Diamond, 2004). Distributed leadership research is at times confusing, due to differing understandings of the term. Regardless of interpretation though, to date, there is little understanding of, and evidence about, the role of system middle leaders in developing shared leadership practices within schools. This paper seeks to contribute to this gap by shedding light on a particular case of a regional Project Officer as a system middle leader, and her work alongside a Principal, as they work to turn school improvement policy into practice.

Sahlberg (2011, p. 104) noted that "the voices of practitioners are rarely heard in the education policy and reform business. Educational change literature is primarily technical discourse created by academics or change consultants." Thus, this paper emphasises the voices of practitioners, articulating their processes for translating policy into enacted school improvement policies and identifying the essential elements of successful leadership (Crowther \& Associates, 2011; Morgan, 2008).

Using distributed leadership (Spillane et al., 2004, p. 29), or shared leadership, as a 'sensing-device' to better understand the complexities involved in school improvement policy enactment, the paper presents a case study of one Queensland geographical region's journey of developing shared leadership practices both at the middle management system level and in schools. This case provides an opportunity to explore different elements of the processes involved in enacting policy as quality school practice highlighting the possibilities inherent in the relationship between school Principals and system middle leaders such as regional Project Officers.

This paper presents a study of one Queensland school community but the findings are relevant to a wider audience due to the phenomenon of global 'policy borrowing' (Lingard, 2010) that ensures practices from one system can be examined to better understand practices in systems with similar policy conditions. The prevalence of the Global Education Reform Movement (Sahlberg, 2011) results in school systems around the globe operating under similar 'school improvement' policies.

\section{Shifting Expectations Regarding Policy Reform}

Harris (2012) emphasised the influence of the Principal in times of rapid reform, noting that at a school level, all change flows through the Principal's office. Stronge, Richard and Catano 
(2008) noted that whilst researchers could identify the major elements of Principals' work, not a great deal was known about how this was carried out in practice. This is an ongoing area of focus, and experts have conducted a significant amount of research on the role of the Principal in school improvement (for examples, see: Fullan, 2007; Hargreaves, Boyle, \& Harris, 2014; Harris et al., 2003; Leithwood et al., 2012; Morgan, 2008). Leithwood et al (2012 described the changing role of the Principal as moving from being an administrator or manager of a school into being directly responsible for student achievement, thus making fewer assumptions that what is happening in classrooms is all good work, and focusing specifically on what is or isn't helping students achieve success (Costante, 2010). Reflecting the shift in expectations of Principal-centred instructional leadership, Leithwood et al. (2012) stated that Principals alone cannot fulfil the instructional leadership needs of a school.

With this in mind the imperative is to develop shared leadership structures that enhance learning outcomes through developing teachers' pedagogical leadership skills. Teachers who achieve excellent outcomes for their students, who understand and connect with diverse student needs, who have discipline expertise, or who make informed pedagogical and curriculum decisions based on data and experience, all have much to contribute to the enactment of policy into effective practice. In order to do this the Principal must be conscious of these skills and build the capacity of teachers to lead quality professional conversations with colleagues. In a similar manner, middle-level system leaders who build the capacity of Principals to empower teacher leaders within their schools develop and enhance regional capacity for school improvement.

The authors of this paper align with the parallel leadership view of shared or distributed leadership practice in that teacher leaders and their Principals should be engaged in collective action to enhance school capacity (Crowther, Ferguson, \& Hann, 2009) and that "teacher leaders and their Principals must deliberate and strategise together for the provision of optimum arrangements and opportunities that lead pedagogical enhancement through a school wide approach" (Conway \& Andrews, 2016, p. 137). Teachers are those most attuned to the needs of their students in their context and as such are integral to the work of Principals when contextualising policy into practice.

\section{Navigating Queensland's Policy Landscape}

Queensland's state schools have been operating under rapidly shifting policy conditions in recent years. The introduction of annual NAPLAN testing in 2008 and Queensland's perceived comparatively poor performance on the inaugural tests served as the catalyst for sweeping reforms intended to improve results in future years.

These reforms were derived from recommendations by external consultants and curriculum authorities (Queensland Department of Education and Training [QDET] 2012a, 2012b). Resulting policies required Principals to adopt the system's improvement agenda and work with 'an unrelenting focus on improved student achievement' (QDET, 2011). Strategies 
within this agenda included a heavy focus on evidence based pedagogical approaches to literacy, numeracy, and science; a focus on specific aspects of education (measurable, for example, by the NAPLAN testing regime); and the requirement for Principals to act as instructional leaders in their schools.

At the same time, the agenda focused on increased autonomy for schools and a devolution of decision-making to the local level whilst remaining focused on school improvement in measurable metrics (see, for example: the School Planning, Reviewing and Reporting Framework, QDETa, 2014). Queensland Principals have therefore been working in a complex space where they must balance the needs of their school community with increasing accountabilities and external requirements being placed upon them by the system and regions in which they work.

\section{Enacting the System Middle Leaders Role as Policy Enablers}

Currently there is little research around the role that the system middle leader level plays within system leadership structures and the translation of policy into practice. What we can agree on is that leadership over many, many years has been, and still is, a "complex phenomenon that involves exercising influence in an organisation and that involves the interplay of many different organisational actions and issues" (Northcraft \& Neale, 1994, p. 344). System leadership has been described as "those who work in central, region and region offices...(including) leaders in schools, who work within a framework of goals, policies, standards, curriculum and accountabilities that is intended to give coherence and consistency to their efforts" (Caldwell, 2011, p. 1).

Effective modern leadership approaches have been explored within a range of innovative initiatives, programs and organisational restructures. David Hargreaves (2011), Michael Fullan (2005), Frank Crowther and associates (2011), and Peter Senge (1990), among others, have championed models for building system improvement through a focus on school improvement by leveraging shared understandings and developing key competencies in partnership with shared accountabilities, all key attributes of a distributive leadership style. Such explanations, however, do little to clarify or differentiate the role of those in the system middle leadership layer of educational system structures, such as that of regional Project Officers within the Queensland Department of Education and Training context, as compared to other forms of leadership roles such as a Director-General or a school Principal, each of which would have reasonably agreed-upon understandings regarding their specific role.

How the various levels of leadership work and how they interact together to improve results within a specific school context is also not clear. Wildy and Clarke (2012, p. 71) noted that school leaders need to have 'contextual literacy', and understand the complexities of their contexts when making decisions. We contend that this need for contextual literacy extends to regional Project Officers as well, who must understand multiple contexts in order to navigate them effectively. 


\section{Differentiating for Local Contexts}

External improvement frameworks are effective in providing a stable point of reflection for planning purposes within broad parameters but unless they are adapted and localised to each school's individual context, they may lead to short-term gains that will not last (Fullan, 2009; Nori, 2011). In the Queensland context, the Australian Council for Educational Research's [ACER] (2011) Teaching and Learning School Improvement Framework is closely aligned to Education Queensland's reforms.

Researchers focused on improving outcomes at a whole-system level (see Hargreaves, 2003; Hargreaves, Lieberman, Fullan, \& Hopkins, 2009; Hopkins, Stringfield, Harris, Stoll, \& Mackay, 2014) have produced guidelines for educators and school systems looking to improve their students' outcomes. One key theme from this wide-scale research has been the importance of considering the needs of the local context, rather than simply adopting a list of strategies that work in 'effective schools' (Fullan, 2005; Hallinger \& Heck, 2011). In addition the literature highlights elements in effective improvement which include the importance of focusing on teaching and improvement at the classroom level rather than the school management level, the importance of leadership, and the importance of commitment and collaboration from all stakeholders (school leaders, staff, community and students) (Hallinger \& Heck, 2011; Harris, 2001; Leithwood \& Jantzi, 2006; Reynolds, 2005) which are all context-specific rather than system specific elements.

Principals play the pivotal role in this contextualisation to address their specific school needs, and they must keep their school's context and needs at the forefront of the agenda. A 'one size fits all' approach is not effective in school improvement. Indeed, Hargreaves (2003) described prescriptive approaches as dangerous, potentially resulting in further inequity in educational outcomes for students of differing socioeconomic circumstances because these prescriptive improvement methods are often used mainly for schools in lower socioeconomic contexts. Fullan, Hill and Crevola (2006) argued that prescriptive improvement strategies can be effective as a starting point for initial success, but the fact remained that school communities must take their individual needs into account when working towards school improvement. Harris (2011) identified that prescriptive improvement strategies are not sustainable, a finding that was supported by Australian research from the Leadership Research International (LRI) team (Crowther \& associates, 2011) highlighting that prescriptive centrally-driven reforms can interfere with the more effective approach of creating a schoolwide pedagogy tailored to local needs and priorities.

Given the importance placed by researchers and experts in the field about contextualising these school improvement frameworks, this paper shifts its focus to an exploration of a case study of a specific school community and its local system context.

\section{The Study}

The study follows the process of a group ('cluster') of geographically-close schools implementing a project designed to build shared leadership capacity, reduce change fatigue 
and leverage teacher leadership for sustainable change. The intent was to introduce this approach both at the middle system level, modelled by the team of Project Officers, and within schools to build shared leadership capacity, acknowledging that the work of teachers has grown in complexity and rigour over many years and yet is still not fully utilised across systems (Crowther et al., 2009).

\subsection{Methodology}

This paper presents a 'participants as co-researchers' (Given, 2008) case study (Yin, 2009), focusing in particular on presenting the experiences of two key policy actors, a system middle leader (regional Project Officer) and a school leader (Principal). The practical translation of policy into practice is illustrated through sharing interconnected and individual experiences related to the translation of policy into practice, firstly within a region and then within one school context. The Research Question being answered was "What implications can be made from understanding the inter-connected roles of a system middle leader (regional Project Officer) and a school leader (Principal) when interpreting and enacting systemic policy and direction?

Participants as co-researchers values the insights of the participants, as experts, who co-analyse the data providing the researcher with "the opportunity to use the experiences and knowledge of the participants to learn about and discuss the research" in more depth (Boylorn, 2008, p. 599). Essential to this approach is immersion by the researchers in the culture and life of the participants (Somekh \& Lewin, 2011). The selection of data collection methods is therefore, vitally important, and in the field, occurs through both direct and indirect means. Direct forms of data collection included the capturing of naturally occurring events, experiences and observations through the participant's recorded narratives. This was supplemented by more indirect means of narrative inquiry conversations with the researcher, allowing for the inflection of tone, scraps of conversation or the importance placed on a story, event or interaction (Hatch, 2002) to be highlighted. The dialogue between the participants and researcher allowed implicit knowledge to come to the fore and be made explicit (Foray \& Lundvall, 1998).

A thematic analysis (Braun \& Clark, 2006) was employed to analyse the data. This was a multi-stage process in which transcripts of the participant's narratives were analysed for recurring themes, which were then condensed and revised into the themes that form the basis of the discussion section of this paper.

\subsection{Participant Roles}

The case study explores policy implementation through the experiences of two participants one system middle leader (regional Project Officer) and one school leader (Principal) - over a two-year period. Both the participants' narratives of their experiences highlighted key interactions and reflections that occurred within their separate but interrelated spaces. These narratives served as the data for analysis by the lead researcher and together with the participants, through narrative inquiry discussion and reflection, became co-researchers and co-authors of this paper seeking to further privilege practitioner voices in school 
improvement research.

Within the context of the research, Education Queensland, a system middle leader is defined as a member of a regional leadership team that is responsible for supporting up to 211 geographically connected schools. Within Education Queensland there are seven regions. The case study explores the role of one system middle leader within one of these regions. The specific system middle leader's role of regional Project Officer is responsible for the provision of localised curriculum policy support to clusters of schools and individual schools within the region. The level of support and specific strategies utilised are directed by the region's Regional Director.

The role of school leader, within the context of this study is identified as a Principal of a primary school that consists of 570 students from diverse socio-economic backgrounds. The Principal leads a teaching team of 1 Deputy Principal, 1 Master teacher, 1 Head of Special Education Services, 1 Business services manager, 49 teachers and 18 teacher aides and support staff. The school has established leadership structures that utilise distributive and teacher leadership. Within the case study the school had been exploring how to enhance their implementation of the systems' school improvement policy with a focus on improving pedagogical practices.

\section{Findings \& Discussion}

Three key themes emerged which highlighted a range of processes intended to support the enactment of school improvement policies at the regional and school levels:

- Theme 1: Building capacity of Principals and teacher leaders to enact policy within context

- Theme 2: Utilising shared leadership practices at all levels, including schools, Principals, and middle system leaders.

- Theme 3: Using evidence-based, contextually-relevant practices to enact policies

The discussion that follows explores these key practices in more depth, using vignettes from the case studies to compare and contrast practices within these themes at the regional and school levels.

\subsection{Building Capacity of Principals and Teacher Leaders to Enact Policy within Context}

A recurring theme within the data focused on the approaches undertaken within the region to build the capacity of Principals to meet the demands of a shifting policy landscape, as well as the subsequent work undertaken by Principals and regional leaders to develop teacher leadership capacity to enact the Department's school improvement reforms. The role of the Regional Project Officer was to develop and help deliver evidence-based approaches to enhance capability development at the regional and school levels. 


\subsubsection{Regional Level: Building Principal Capacity}

As part of a wider team of colleagues, the Regional Project Officer led the translation of education policy into a series of professional learning modules, aimed at developing Principals' capacity for leading school improvement through scaffolded leadership development. This reflects the importance of the role of the Principal in leading improvement (Harris, 2012), while emphasising the importance of sharing the leadership of school improvement among the school staff, it being difficult for Principals to serve as lone instructional leaders (Leithwood et al., 2012). Each module utilised research and evidence based practices with the aim of building the capability of regional instructional leaders to enact and contextualise policy implementation beyond rhetoric into sustained practice. The Project Officer described a process of 'braiding' core state and regional priorities, guiding the way policy was interpreted by regional policy actors who contextualised and translated it into modules for learning. The purpose of the modules was to promote leadership that enabled policy enactment whilst not increasing teacher stress levels or negatively impacting on student learning outcomes. The distributed approach reflects Crowther, Ferguson and Hann's (2009) vision of collective action for school improvement and as such, the focus for the modules became the fostering of quality teaching practices, given the system-wide focus on the development of schoolwide pedagogical frameworks (Conway \& Andrews, 2016). The modules recognised that Principals may need help in building shared leadership capacity at the school level. At the same time, the project officers needed to seek and reflect upon feedback throughout the process to ensure that this support was contextualised, relevant to Principals' 'real worlds', and ongoing.

After seeking feedback from the Region's Principals, we identified a need to promote and support shared leadership structures and processes aimed at developing purposeful collaborative partnerships between school leadership teams and teachers for sustained pedagogical improvement. This feedback was utilised to position the importance of utilising deliberate, transparent reflective practices to build capability based on distributive leadership concepts and utilising teacher pedagogical leadership conceptualised as parallel leadership.

Vignette 1: Regional Principal Capacity Building

The feedback gathered by the Project Officer (within NHMRC protocols), after Principals participated in the modules, included comments about the relevance to Principals' work in schools, and reflections that Principals felt more confident to implement evidence-based practices of coaching and feedback for school improvement.

\subsubsection{School Level: Building Teacher Leader Capacity in Schools}

Principals had the opportunity to call upon Regional Project Officers for support in developing leadership capacity at a school level to ensure the adoption of successful practices in school change processes. Shared leadership within the school had already been established, 
drawing on the work of Crowther et al. (2009) and Crowther and associates (2011). The regional project resonated with the Principal's existing way of working and allowed her to expand on this. The Principal and school leadership team (including a Deputy Principal and Head of Special Education) along with teacher leaders identified by the formal school leadership team were already acknowledged and a teacher-led School Management Team [SMT], consisting of teacher representatives, had been in operation for some years. In the case study school, the aforementioned modules and the support from the Project Officer enabled the Principal to build on the shared leadership already in existence. The approach taken was to develop coaching capacity within key staff members who would then work with others in a non-threatening manner reviewing pedagogical strategies that both included and challenged students to achieve. This added yet another layer of parallel leadership to the SMT which meets monthly with representatives from each year level on a rotating basis, so that every teacher is able to be part of the SMT meetings throughout the year. The SMT is responsible for the development and monitoring of the School Improvement Agenda, and thus responsible for the successful translation of departmental school improvement policies into practice. The distributed approach to leadership contributes to the success of these practices (Lewis \& Andrews, 2009; Spillane et al., 2004) and once again reflects the research suggesting that the Principal should not, or could not, be solely responsible for the instructional leadership of a school (Leithwood et al., 2012).

We first formed a teacher led SMT many, many years ago as a result of a school improvement journey called the Innovative Designs for Enhancing Achievement in Schools [IDEAS] Project [Crowther, Andrews, Morgan \& O'Neill, 2012] ... this region project has enabled me to now expand the leadership capability within a core group. Initially we worked with our region Project Officer on the basics of coaching for pedagogical improvement. Each of my team are now coached by me regularly so they can continue to build their capacity to interact effectively with other staff by creating trusting relationships with our classroom teachers. This team leadership structure enables our school to develop purposeful partnerships between my team and classroom teachers. If this layer doesn't happen within a school, sustained pedagogical improvement isn't embedded. Data doesn't improve and transparency of practice is lost. Schools can then fall into the trap of looking for other change practices and the opportunity for growth and unpacking the true meaning of reflective processes are not utilized.

Vignette 2: School Management Teams for Improved Student Outcomes

The emphasis placed by the Principal on the importance of trusting relationships and teamwork is reflective of the role that a positive culture plays within a school and highlights the second theme regarding the significance of collaboration and aligned shared leadership at all levels of the policy enactment process. This approach is also representative of the research 
showing the importance of commitment and collaboration from all stakeholders (Hallinger \& Heck, 2011; Harris, 2001), and shows the importance placed by the Principal on this development of teacher leaders.

7.2 Encouraging Shared Leadership at all Levels, Including Schools, Principals, and Regional Staff Members

The case study emphasised the centrality of collaboration in the success of change processes for the enactment of school improvement policies. The key notions recurring within the data as part of this broader theme were the importance of understanding the strengths of a team and utilising these in a targeted manner, while developing capacity for shared leadership and providing diverse opportunities to take on leadership roles in a project or a change process. These themes reflected the research from Crowther and associates (2011) that emphasised the importance of schoolwide collaboration on approaches to pedagogy and improving student achievement.

\subsubsection{Regional Level: Shared Leadership among system middle leaders.}

Not only was collaboration at the school level necessary, as highlighted in Vignette 2, but a newfound collaboration at the regional level was necessary so that the effectiveness of Principal capability development and support was maximised. Each of the Regional Project Officer's portfolios had previously been independent of each other, while still strategically connected through regional and Departmental vision and priorities. However, it was determined early in the project that the team needed to collaborate more effectively to ensure a consistent approach to supporting the enactment of policy at a school level. This is indicative of Northcraft and Neale's (1994, p. 344) findings that successful leadership at this level involves 'the interplay of many different organisational actions'. These actions included the Project Officer team electing to work across their strengths and previously independent portfolios.

We identified significant differences between each portfolio's operational and staffing models as well as differing measures for accountabilities. In order to progress we decided at the regional level to work in a co-ordinated way. This meant joint planning and project based co-ordination whilst other portfolio priorities would remain separate. As we began to frame our thinking, our direction became clearer and we identified the natural connections between our work. What became apparent was a large difference in the metalanguage we used to communicate with schools and we collectively agreed that the streamlining of messages required a shared and consistent metalanguage. While 100\% of inter portfolio members indicated that this model had improved the efficiency and transparency of policy translation at a regional level and the streamlining of policy messages had become quite smooth, the planning for how to deliver and implement at a school cluster level was more complex.

Vignette 3: Collaboration at a System Middle Leader Level 
Collaboration therefore enhanced the regional support offered through the modules, by ensuring evidence-based practices were the foundation of Principals' capability development, as well as promoting discussion and reinforcement of these in a consistent manner, using shared language, by all staff at all levels of the region. The 'coherence and consistency' (Caldwell, 2011, p. 1) of these efforts served to further support schools in their improvement efforts. The importance of a shared and consistent metalanguage is reflective of aspects of metastrategic leadership and alignment (Crowther et al., 2009) and translates to a regional priority of developing evidence-based practices that were contextually relevant but consistent across the region. The Project Officer noted that collaboration was required at a school level to develop 'collective understandings, not only of the knowledge and skills required but more importantly of how to support each other' as they sought to improve pedagogical practices.

7.2.2 School Level: Shared Leadership within Schools

Getting into classrooms to observe classroom practice and delivery of curriculum is essential, as assumptions about the level of children's learning doesn't give you a comprehensive story that aligns with the school improvement agenda. However, Principals can't physically get to every classroom consistently to develop and provide quality insights into practices that are either supporting or hindering success in learning. This is where the development of your "team" is important. I have a team of eight key staff members (Deputy, HOSE, Learning Support teachers, coaches, Gifted and Talented teacher and Master Teacher) who together with myself, drive our School Improvement Agenda. Over a number of years, I have actively encouraged, supported and nurtured the team members' capacity for leadership and this has enabled me to build with them, trust, passion and an energy for developing quality learning partnerships with all of our staff. The selection of your team, I think is an important key, in that you need to have credibility and acceptance from the remainder of the staff for the team, especially when they are leading change and driving an improvement agenda that can be quite confronting at times. We drew on the expertise of a member of the Regional Educational Project Team and together we participated in extensive quality professional development. Each member of my team, together with myself underwent coaching training for two terms. It was meaningful, timely and focused on "our" context. Once we were confident with our coaching practices we developed a mode of delivery that suited our school.

Vignette 4: Developing Teacher Leaders for Collaborative School Improvement

The case study data showed that the Principal actively engaged with her school's data, staff and parent community to really 'know' her school, and understood that frameworks and prescriptive steps do not translate into long-term deep change in schools. Rather, it is knowing context (Wildy \& Clarke, 2012) and developing quality relationships (Andrews \& Abawi, 2016) that matters. As such, the Principal actively developed an empowering school culture so the school community and staff had essential ownership of improvements and 
outcomes. To do so, she discovered the strengths of her team and utilised these in a targeted manner whilst also actively seeking and building capacity of potential teacher leaders, drawing together a strong and committed team to help drive the improvement agenda and translate school improvement policy into practice.

From this vignette, it is clear that the Principal recognised quality relationships as the key to developing trusting partnerships that enable discussion and reflection at the micro-pedagogical level (Andrews \& Abawi, 2016).

\subsection{Using Evidence-Based, Contextually-Relevant Practices to Enact Policies}

The literature reinforced the importance of contextualising school improvement processes (Fullan, 2005; Hallinger \& Heck, 2011), which is where we contend that some of the complexities lie for Regional Project Officers in relation to their 'contextual literacy' (Wildy $\&$ Clarke, 2012, p. 71). Working with a large number of schools means they need to be able to quickly acquire knowledge and understanding of each school's contextual strengths and needs. The urgency of the reform policy agenda also resulted in a need for evidence-based practices that could be adapted to meet each school's contextual needs.

\subsubsection{Regional Level: Evidence-Based Practices}

At a regional level, the team needed to be able to base decisions on research and keep strategic policy at the forefront of planning, to ensure policy enactment and metalanguage aligned with the system's strategic agenda. The translation of policy into the local context (Fullan, 2005; Hallinger \& Heck, 2011) proved to be a key driver for the team's work, and the use of action learning alongside collaborative environments meant that Principals were able to reflect on their understandings and current practices in a supportive environment.

Utilising Instructional Leadership theory (Hallinger, 2004), we decided to use the evidence based pedagogical practices we were unpacking. This involved deliberately using structures to model active participation, higher order thinking, proactive behaviour management strategies and differentiation at the whole group level. In addition to this adult learning theories such as Kolb (1984) and Schön (1987) were incorporated through reflective processes. With this in mind, each module's design incorporated "braided" policy specific requirements underpinned by leadership and change management theory.

Participants (Principals and school leadership teams) unpacked the policy content by actively participating in reflective processes that could be taken back to their individual school context. This provided participants with the opportunity to experience the thinking and reflective practices required to develop shared understandings and engage in meaningful conversations about pedagogy. The value of utilising reflective processes within the module design structure was again reflected in feedback from Principals, where it became increasing evident that the pragmatic processes that leaders'valued within the modules addressed the cultural change factors of unpacking individual assumptions, beliefs, expectations and habits.

Vignette 5: Modelling Evidence-Based Pedagogical Practices 
Principal survey data indicated that this approach was deemed to be highly effective, and the use of distributive leadership processes at the regional and school level enabled teams to collectively harness multiple perspectives to inform policy translation and strategy implementation (Crowther and associates, 2011; Senge, 1990). The clear focus on "how" to develop capability was also highlighted, paving the way for deep pedagogical conversations and changes in the way the region views and enacts professional learning for improved student outcomes (Andrews \& Abawi, 2016). Annual anonymous regional survey data prior to the project resulted in $64 \%$ of teachers indicating they received helpful feedback from their school in relation to their work. Two years later, after the project, this increased to $94.3 \%$ of teachers. This feedback from participants and teacher surveys indicated that the model for translating policy into practice had a positive impact on teachers within the region. At a school level, these change and improvement process were translated into practices that addressed the contextual needs of each school community.

\subsubsection{School Level: Evidence-Based Practices}

As a team, we realized that to progress our school improvement agenda, we had to reignite teacher passion for their craft. The key to improving our learning outcomes for students lay with the classroom teachers. We needed to enhance current pedagogical practices and deepen the quality of curriculum delivery in the classroom. We had to provide quality time for teachers to have regular opportunities to participate in reflective conversations about their craft, examine current research and provide feedback on explicit teaching practices in classrooms.

The Strategic Management Team (SMT) meetings are essential in building a shared understanding of Vision and direction within the school and by the end of a year everyone has had a chance to be part of the SMT culture. At these meetings, we look at Professional Readings, Policies, Improvement Strategies and Data and the impact they have on the school. My Master Teacher chairs these meetings and this allows me to be an observer and a coach for the discussion that evolves throughout the meeting. These SMT representatives are then accountable for sharing the learnings from the SMT with their cohort members. This process supports the metalanguage of alignment throughout the school to support consistency of practice and understanding of our school's journey of learning. Vignette 6: Contextualising Evidence-Based Practices as a Team to Enact School
Improvement Policy

In the case study school the Principal reflected on the need to take personal responsibility to read and understand system requirements, policies and accountability expectations. Ensuring thorough and in-depth knowledge of these requirements and systemic directions allowed her to filter and contextualise these for her school community. Adherence to a specific process or framework with mandated steps for delivery does not give long term gains (Fullan, 2009; Nori, 2011), instead it is knowing context through thorough investigation of school data, both qualitative and quantitative, which will help determine which evidence based practices might 
best move student outcomes forward. Deep critically reflective evaluation and research into current classroom practices and trialling tools, options and available supports are dependent on the quality of the relationships across the various levels of interaction. The Principal and all members of their leadership team need to understand and actively develop an empowering school culture so the school community and staff have essential ownership of the need for improvements and the celebration of outcomes. By building on strategies with proven success (such as the SMT meetings) staff can spend time on contextualising and personalising these for the students in their classroom (Fullan, 2005; Leithwood \& Jantzi, 2006; Reynolds, 2005).

\section{Conclusion}

This case study presented experiences at the Regional and School leadership levels. The lived experiences resonate with each other and the 'participants as co-researchers' approach allowed participants to add depth to the data showing the complexities inherent in translating large-scale school improvement policies into the local school context. Participants presented nuanced differences in the case according to purpose and process but underpinning principles at both the regional system level and the contextualised school practice level are alike. Both perspectives clearly state that 'the people' are what matter.

Too often past change processes have been imposed from the top with little acknowledgement or consideration of those who action these changes. Ultimately it is well-being, trust, and the creation of safe spaces for reflection and personal growth that underpin effective capacity building for change and improvement, at the system and school level, and the leadership and pedagogical level. Taking a strength based approach sets the scene for engagement and a willingness to take risks and try new approaches for tackling ongoing challenges. It is also from this basis of trust and empowerment that distributed leadership practices can be developed, or in this case enhanced, in partnership with aligned systems thinking.

The interpreting and actioning of systemic policy is acknowledged as a challenging task. In this study, it was supported at the regional level by project officers really listening to the needs of Principals and schools, targeting support accordingly. This ensured that the options, resources and professional development provided at the collective leadership level were 'hitting the target' at the Principal and school level (Crowther, Andrews, Morgan, \& O'Neill, 2012).

In turn, what can be seen at the Principal level is metastrategic thinking (Andrews \& Abawi, 2016; Crowther, Ferguson \& Hann, 2009; Morgan, 2008) over the long term. This thinking is exemplified by a sense of responsibility for personal learning and a commitment to keeping up to date with policy and new initiatives. To facilitate change, regional shared leadership has been drawn upon in a targeted way built on a thorough knowledge of the strengths and challenges present within the specific school contexts. The Principal made it very clear that for the approach taken to work, there must be prior commitment to building a learning culture that supports critically reflective practice in a safe and supported manner. If all the pieces are 
in place it becomes possible for a systems approach such as this, to create a language of alignment that can be seen and heard across all levels of the system. But mostly importantly, policy can be 'lived' through micro-pedagogical deepening (Andrews \& Abawi, 2016) at the classroom level where ultimately any school improvement agenda needs to come to fruition.

\subsection{Implications for Future Practice}

Participant/co-researcher insights identified that the broader comments and feedback from the regional Principals who undertook the various modules developed by the regional system middle leadership team, indicated that the braiding approach taken was an excellent starting point for them to develop and contextualise the policy into practice requirement, as was the cascading shared leadership coaching model used effectively in the case study school. The complexity of sharing development of direction and resources at the regional middle system level cannot be underestimated. To avoid competing priorities and misunderstandings it is important to ensure understandings align, from the metalanguage up.

Shared leadership partnerships between middle-system leaders and Principals can be utilised to maximise school outcomes within regions. In order for this to occur, the Principal must have a thorough understanding of their school, their staff and their current capabilities, as well as school specific student needs. In that way interventions and enhancements can start at various points within a continuum because no 'packaged' process provides the type of flexibility and adaptability that allows for true ownership of a school improvement agenda within context. Fundamentally, it is the relationships carefully nurtured within the school and between school and system, that create the environment upon which teacher leadership and pedagogical leadership can flourish.

\subsection{Implications for Future Research}

The authors propose that, although a small case study, this research provides insights into the lived experiences of enacting complex change and improvement policy agendas. To better understand the processes and approaches that support diverse practitioners who have successfully translated policy into practice within their own contexts the authors aim to continue this research by broadening the scope of this study to include Principals from other schools. The findings from this study will be used as a starting point for comparative analysis. Further study of cases from within this region will provide an interesting lens into the impact of individual leaders and whether their philosophies or styles make a significant difference to the translation of policy into practice.

This article presents a contribution to the field's understanding of the impact of a school improvement policy agenda at a local district level. The contribution of practitioner voices (Sahlberg, 2011, p. 104) and perspectives provides a nuanced glimpse into extremely complex and, by nature, contextualised processes that further highlights the need for support and evidence-based capability development of the people at all levels who are leading this change. 


\section{References}

Andrews, D., \& Abawi, L. (2016). Three-dimensional pedagogy: A new professionalism in $\begin{array}{lllll}\text { educational contexts. } \quad \text { Improving } & \text { Schools, } & \text { 20(1), } & \text { 1-19. }\end{array}$ https://doi.org/10.1177/1365480216652025

Andrews, D., \& Crowther, F. (2002). Parallel leadership: A clue to the contents of the black box of school reform. The International Journal of Educational Management, 16(4), 152-159. https://doi.org/10.1108/09513540210432128

Australian Council for Educational Research [ACER]. (2011). Teaching and Learning School Improvement Framework. Retrieved from http://www.acer.edu.au/c2e

Bolden, R. (2011). Shared leadership in organisations: A review of theory and research. International Journal of Management Reviews, 13, 251-269. https://doi.org/10.1111/j.1468-2370.2011.00306.x

Boylorn, R. M. (2008). Participants as co-researchers. In M. Given (Ed.), The SAGE Encyclopedia of Qualitative Research Methods (pp. 599-601). London, UK: SAGE Publications, Inc. http://dx.doi.org/10.4135/9781412963909.n310

Caldwell, B. (2011). School autonomy and system leadership: Aligning the effort in the journey from improvement to transformation. Paper presented at National Symposium, Queensland Education Leadership Institute, Brisbane.

Costante, K. (2010). Evolving Perspectives: Leaders and Leadership. In Conversation, 2(2). Retrieved from http://www.edu.gov.on.ca/eng/policyfunding/leadership/winter2010.pdf

Crowther, F., \& Associates. (2011). From school improvement to sustained capacity: the parallel leadership pathway. Thousand Oaks, CA: Corwin Press.

Crowther, F., Andrews, D., Morgan, A., \& O’Neill, S. (2012). Hitting the bullseye of school improvement: The 'IDEAS' project at work in a successful school system. Leading \& Managing, 18(2), 1-33.

Crowther, F., Ferguson, M., \& Hann, L. (2009). Developing teacher leaders: How teacher leadership enhances school success (2nd ed.). Thousand Oaks, CA: Corwin Press.

Foray, D., \& Lundvall, B. (1998). The knowledge-based economy: from the economics of knowledge to the learning economy. The economic impact of knowledge, 115-121. https://doi.org/10.1016/B978-0-7506-7009-8.50011-2

Fullan, M. (2005). Leadership and sustainability: Systems thinkers in action. Thousand Oaks, CA: Corwin Press.

Fullan, M. (2007) Achieving Large-Scale Reform. In R. Maclean (Ed.), Learning and Teaching for the Twenty-First Century (pp.137-144). Netherlands: Springer. https://doi.org/10.1007/978-1-4020-5773-1_8

Fullan, M. (2009). Large-scale reform comes of age. Journal of Educational Change, 10(2), 
101-113. https://doi.org/10.1007/s10833-009-9108-Z

Fullan, M., Hill, P., \& Crevola, C. (2006) Breakthrough. California: Corwin Press

Gronn, P. (2002). Distributed leadership as a unit of analysis. Leadership Quarterly, 13, 423-451. https://doi.org/10.1016/S1048-9843(02)00120-0

Hallinger, P., \& Heck, R. (2011). Exploring the journey of school improvement: classifying and analysing patterns of change in school improvement processes and learning outcomes. School Effectiveness and School Improvement, 22(1), 1-27. https://doi.org/10.1080/09243453.2010.536322

Hargreaves, A. (2003). Teaching in the Knowledge Society. New York: Teachers College Press.

Hargreaves, A., Boyle, A., \& Harris, A. (2014). Uplifting Leadership. San Francisco: Jossey Bass.

Hargreaves, A., Lieberman, A., Fullan, M., \& Hopkins, D. (Eds). (2009). Second International Handbook of Educational Change. Netherlands: Springer. https://doi.org/10.1007/978-90-481-2660-6

Hargreaves, D. (2011). System redesign for system capacity building. Journal of Educational Administration, 49(6), 685-700. https://doi.org/10.1108/09578231111174820

Harris, A. (2001). Contemporary Perspectives on School Effectiveness and School Improvement. In D. Hopkins \& D. Reynolds (Ed.), School Effectiveness and School Improvement. London: Continuum.

Harris, A. (2011). System improvement through collective capacity building. Journal of Educational Administration, 49(6), 624-636. https://doi.org/10.1108/09578231111174785

Harris, A. (2012). Shared Leadership: Implications for the Role of the Principal. Journal of Management Development, 30(1), 7-17.

Harris, A., Day, C., Hadfield, M., Hopkins, D., Hargreaves, A., \& Chapman, C. (2003). Effective Leadership for School Improvement. London: RoutledgeFalmer.

Hatch, J. A. (2002). Doing qualitative research in education settings. Albany: State University of New York Press.

Hooge, E. (2016). Editorial: Governance dynamics in complex decentralised education systems. European Journal of Education, 51(4), 425-430. http://dx.doi.org/10.1111/ejed.12192

Hopkins, D., Stringfield, S., Harris, A., Stoll, L., \& Mackay, T. (2014). School and system improvement: a narrative state-of-the-art review. School Effectiveness and School Improvement, 25(2), 257-281. https://doi.org/10.1080/09243453.2014.885452

Keast, R. (2008). Closing gaps and opening doors: the function of an integrated 


\section{Macrothink}

homelessness service system. Department of Communities. Queensland.

Leithwood, K., \& Jantzi, D. (2006). Transformational school leadership for large-scale reform: Effects on students, teachers, and their classroom practice. School Effectiveness and School Improvement, 17(2), 201-227. https://doi.org/10.1080/09243450600565829

Leithwood, K., Jantzi, D., \& Steinbach, R. (2012). Changing Leadership for Changing Times. Philadelphia: Open University Press.

Levin, B., \& Fullan, M. (2009). Learning about system renewal, Educational Management, $\begin{array}{llll}\text { Administration } \quad \& \quad \text { Leadership, } & \text { 289-303. }\end{array}$ https://doi.org/10.1177/1741143207087778

Lewis, M. \& Andrews, D. (2009). Parallel leadership: changing landscapes for Principals. In: N. Cranston \& L. Ehrich (Eds.), Australian school leadership today (pp.141-164). Brisbane: Australian Academic Press.

Lewis, M., \& Andrews, D. (2004). Parallel leadership for 21st century schools. Access, 18(4), $5-8$.

Lingard, B. (2010). Policy borrowing, policy learning: Testing times in Australian schooling. $\begin{array}{llll}\text { Critical Studies in } & \text { Education, } & \text { 51(2), } & \text { 129-147. }\end{array}$ http://dx.doi.org/10.1080/1750848100371026

Michel, A. (2016). Complex education systems: From steering change to governance. European Journal of Education, 51(4), 513-521. http://dx.doi.org/10.1111/ejed.12186

Morgan, A. (2008). The Principal in a process of school revitalisation: A metastrategic role. Available from https://eprints.usq.edu.au/4077/

Nori, J. (2011). School Improvement: Why, What, How and Who. Principal Leadership. September, 65-66.

Northcraft, G., \& Neale, M. (1994). Organizational Behaviour: a management challenge (2 ${ }^{\text {nd }}$ Ed). Orlando: Dryden.

Queensland Department of Education and Training [QDET]. (2011). United in our Pursuit of Excellence. Brisbane, Australia: Queensland Government.

Queensland Department of Education and Training [QDET]. (2012a). A Shared Challenge: Improving Literacy, Numeracy and Science Learning in Queensland Primary Schools. Retrieved from http://education.qld.gov.au/mastersreview/pdfs/final-report-masters.pdf

Queensland Department of Education and Training [QDET]. (2012b). Education Queensland System Review: Final Report (Michael Fullan and Ben Levin Report). Education Queensland Response. Retrieved from http://education.qld.gov.au/publication/production/reports/docs/queensland-education-sy stem-review.pdf

Queensland Department of Education and Training [QDET]. (2014). School Planning, 
Reviewing and Reporting Framework Retrieved from http://education.qld.gov.au/strategic/accountability/pdf/sprr-framework.pdf

Reynolds, D. (2005). World Class School Improvement: An Analysis of the Implications of Recent International School Effectiveness and School Improvement Research for Improvement Practice. In D. Hopkins (Ed.), The Practice and Theory of School Improvement (pp 241-251). Springer. https://doi.org/10.1007/1-4020-4452-6_13

Sahlberg, P. (2011). Finnish Lessons: What Can the World Learn from School Reform in Finland? New York: Teachers College Press.

Scott, R. (2013). Institutions and organizations: Ideas, interests and identities. Thousand Oaks, CA: Sage Publications.

Senge, P. M. (1990). The fifth discipline: The art and practice of the learning organization. New York: Doubleday/Currency.

Somekh, B., \& Lewin, C. (2011). Research methods in the social sciences (2nd ed.). London: SAGE

Spillane, J. P., Halverson, R., \& Diamond, J. B. (2004). Towards a theory of leadership practice: a distributed perspective. Journal of Curriculum Studies, 36, 3-34. https://doi.org/10.1080/0022027032000106726

Stermann, J. (1994). Learning in and about complex systems. System Dynamics Review, 10(2-3), 291-330. http://dx.doi.org/10.1002/sdr.4260100214

Stronge, J., Richard, H., \& Catano, N. (2008). Qualities of Effective Principals. Virginia, US: ASCD.

Wildy, H., \& Clarke, S. (2012). Leading a small remote school: in the face of a culture of acceptance. Education, 40(1), 63-74. http://dx.doi.org/10.1080/03004279.2012.635057

\section{Copyright Disclaimer}

Copyright for this article is retained by the author(s), with first publication rights granted to the journal.

This is an open-access article distributed under the terms and conditions of the Creative Commons Attribution license (http://creativecommons.org/licenses/by/3.0/). 